\title{
The effect of pre-exposure to complex stimuli on activity in a novel environment
}

\author{
GERALD W. MORLOCK \\ North Carolina State University, Raleigh, North Carolina 27605 \\ and \\ MERLE E. MEYER \\ University of Florida, Gainesville, Florida 32601
}

\begin{abstract}
A hypothesis, derived from the optimal level of arousal hypothesis and formulated to account for the decrease in activity over time in a novel environment, was investigated. Exposure to complex stimuli immediately prior to a 12-min activity session significantly lowered general locomotor activity of mice but did not effect the rate of the activity decrement.
\end{abstract}

Several experiments have demonstrated that the general locomotor activity of rodents decreases as a function of time spent in a novel environment (i.e., Brown, 1968; Carr \& Williams, 1957; Gerben, 1967; Glickman, 1958; Halliday, 1967). This phenomenon has been interpreted as habituation to the novel environment by Walters and Block (1969), and the rate of the decline has been used as an index of habituation by Glickman and Hartz (1964). Two different sources of evidence suggest that this interpretation may be questionable. The activity of the golden hamster (Hughes, 1969) and the chick (Morlock, Frank, \& Meyer, 1971) increases rather than decreases as a function of the number of minutes spent in a novel environment. This evidence at least restricts the generality of the habituation interpretation.

Several investigators (Browman, 1942; Lester, 1967; Wimer \& Stern, 1964) have demonstrated that rodents suffering sensory loss are more active than controls. Glickman (1958) and Klein and Brown (1969) have interpreted this phenomenon as supporting Hebb's (1955) optimal level of arousal hypothesis. Recently, Morlock and Meyer (1971) gave further support to this hypothesis by demonstrating that blinded rats are more active in simple than complex environments. It may be hypothesized that rodents placed in a novel environment are initially quite active in order to raise their arousal level to some optimal point and that as this point is reached activity begins to decrease. If this hypothesis is to account for the rapid decline of activity in a novel environment, then rodents receiving exposure to complex stimuli immediately before being placed in a novel environment should be less active and exhibit a smaller decrease in activity over time than rodents not receiving pre-exposure to complex stimuli.

\section{METHOD}

Subjects

The subjects were 66 male 56-day-old Swiss-Webster albino mice. Upon receipt, they were housed 16-17 per cage and placed in an isolated room on ad-lib food and water under a 12-h-on/ 12-h-off lighting schedule. All animals were then housed in individual cages for a 1 week period immediately prior to the start of the study (Essman, 1966).

\section{Apparatus}

A Greek cross maze was used to expose one group of animals to a complex array of stimuli. The four outside compartments of the $24-\mathrm{cm}$-high maze were $12 \mathrm{~cm}$ wide x $16 \mathrm{~cm}$ long. One of the compartments was painted completely white, one completely black, one had 1-cm-wide black diagonal stripes on a white background, and another was finished in a black and white checkerboard pattern. The floor of the center compartment was painted flat gray, but the floor of each of the outside compartments was covered with one of the following materials: window screen, fine, medium, or coarse grade sandpaper.

General activity was measured in a box measuring $24 \mathrm{~cm}$ wide $\times 32 \mathrm{~cm}$ long $\times 10 \mathrm{~cm}$ high. Three Plexiglas partitions (16 cm long $\times 10 \mathrm{~cm}$ high) were positioned such that the animal was forced to cross from side to side when traversing the length of the box. The entire apparatus was painted flat gray, except for circles $(1.5 \mathrm{~cm}$ in diam) on each of the Plexiglas partitions which allowed an infrared photobeam to pass the length of the box approximately $1.5 \mathrm{~cm}$ above the floor an equal distance from both sides. The number of photobeam disruptions served as the measure of activity and was automatically recorded on a print-out computer. The top of the activity box consisted of a piece of white translucent plastic $26 \mathrm{~cm}$ wide $\times 34 \mathrm{~cm}$ long. Four such activity boxes were arranged on a table in two rows of two each, separated by approximately $10 \mathrm{~cm}$. A blower located in the same room provided masking noise.

\section{Procedure}

The mice were randomly divided into two equal-sized groups. The mice in the exposed group were placed (in pairs) in the Greek cross maze for a 20 -min period immediately prior to the activity test. The animals in the nonexposed group were taken directly from their individual home cages and placed in the 


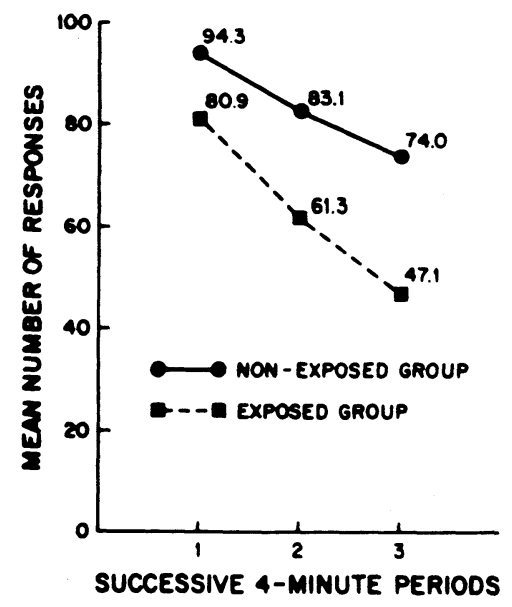

Figure 1. Mean locomotor activity as a function of pre-exposure treatments and successive 4 -min periods within the activity test.

activity boxes. Four animals (two of the exposed group and two of the nonexposed group) were tested simultaneously. At the conclusion of the $12-\mathrm{min}$ activity test, all mice were returned to their individual home cages.

\section{RESULTS AND DISCUSSION}

The activity data was analyzed as a two-factor mixed analysis of variance, with successive 4-min periods within the 12 -min activity test as the repeated measures variable (Lindquist, 1953, Type I). Only the between-groups effect $(\mathrm{F}=4.209, \mathrm{df}=1 / 64, \mathrm{p}<.05)$ and the repeated measures effect $(F=18.720, \mathrm{df}=2 / 128, \mathrm{p}<.05)$ were significant. As can be seen in Figure 1, the exposed group was consistently less active than the nonexposed group, and activity in both groups decreased as a function of time in the novel environment. The hypothesis that pre-exposure to complex stimuli would reduce activity in a novel environment was supported. However, the hypothesis that pre-exposure to complex stimuli would effect the rate of the decrease in activity as a function of time in a novel environment was not supported in that no interaction effect was obtained. It appears that prior exposure to complex stimuli results in an overall lowering of activity in a novel environment but that the rate of decline of activity is not affected.

\section{REFERENCES}

Browman, L. G. The effect of bilateral optic enucleation of the voluntary muscular activity of the albino rat. Journal of Experimental Zoology. 1942. 91. 331-344.

Brows. K. Vaginal stimulation and exploratory behavior in the rat. Animal Behavior. 1968. 16. $534-53^{-}$.

CARR. R. M.. \& Williams. C. D. Exploratory behavior of three strains of rats. Journal of Comparative and Phisiological Psichologi. 195- . 50. 621-623.

Essmas. W. B. The development of activity differences in isolated and aggregated mice. Animal Behavior. 1906. 14. 406-409.

Gerben. M. J. Hypoxia and spontaneous locomotor activity in the rat. Perceptual and Motor Skills. 196- 25. 969-9-8.

Glickman. S. E. Effects of peripheral blindness on exploratory behavior in the hooded rat. Canadian Journal of Psichology: 1958. 12. $45-51$

Glickman. S. E.. \& Hartz. K. E. Exploratory behavior in several species of rodents. Journal of Comparative and Physiological Psychology. 1964. 58. 101-104.

Halliday. M. S. Exploratory behavior in elevated and enclosed mazes. Quarterly Joumal of Experimental Psichologi. $196^{-} .19$. $254-263$.

HeBb. D. O. Drives and the CNS (conceptual nervous system). Psychological Review. 1955. 62. 243-254.

HcGHEs. R. N. Exploration in three laboratory rodents. Perceptual and Motor Skills. 1969. 28. 90.

KLEIN. D. \& BRows. T. S. Exploratory behavior and spontaneous alternation in blind and anosmic rats. Journal of Comparative and Physiological Psichology. 1969. 68. 10 $10^{-}-110$.

LESTER. D. Exploratory behavior in peripherally blinded rats. Psichonomic Science. $196^{-} .8{ }^{-}-8$.

LiNDQuist. E. F. Design and analisis of experiments in psychology and educution. Boston: Houghton Mifflin. 1953.

Morlock. G. W.. Frank. L. H.. \& Meyer. M. E. Activity in chicks as a function of visual loss and within test duration. Psichonomic Science. 19-1. 24. 200.

Morlock. G. W. \& Meyer. M. E. Activity of blinded rats in tactually simple and complex environments. Psychonomic Science. 19-1. 23. 355-350.

Walters. G.. \& Block. R. G. Scopolamine effects on locomotor and exploratory activity in rats. Psichonomic Science. 1969. 17. 3-4.

WIMER. R.. \& STERN. H. Controlled visual input and exploratory activity in C5-B1 6J mice. Perceptual and Motor Skills. 1964. 18. $299 \cdot 30^{-}$.

(Received for publication July 18, 1975.) 